Artikel Penelitian

\title{
Penghitungan Beban Kritis pada Struktur Balok-Kolom Akibat Pembebanan Secara Aksial dan Lateral Berbasiskan Metode Beda Hingga
}

\author{
Eka Satria, Nusyirwan, Deri Yunifki \\ Jurusan Teknik Mesin Universitas Andalas, Kampus Limau Manis, Padang, 25133, Indonesia
}

INFORMASI ARTIKEL

\section{Sejarah Artikel:}

Diterima Redaksi: 04 Agustus 2017

Revisi Akhir: 01 September 2017

Diterbitkan: 31 Oktober 2017

\section{KATA KUNCI}

Balok-Kolom

Beban Kritis

Metode Beda Hingga

Beban Aksial dan Lateral

KORESPONDENSI

E-mail: ekasatria@ft.unand.ac.id

\begin{abstract}
A B S T R A C T
This paper is aimed to determine the critical buckling load of the beamcolumn structures for practical applications. Firstly, the critical buckling loads is calculated numerically based on finite difference method. For geometrical modeling, the structures are supported in three types of supports; pinnedroller, fixed-free, and fixed-pinned. Then, a geometry of the beam is varied in variation of slenderness ratio. The load is given in types of uniform distribution load, q, laterally and a concentrated load, P, axially. Using a computational program, the relationships of $\mathrm{P} / \mathrm{q}$ to slendernes ratio, $\lambda$, for all models are determined. The results then are approached by regression technique of a least square method in order to find a the best fit of equation. This equation is recommended as a practical equation for determining the critical buckling of the beam-column structures under variation of types of supports, slenderness ratio and rasio $\mathrm{P} / \mathrm{q}$.
\end{abstract}

\section{PENDAHULUAN}

Balok-kolom merupakan jenis struktur yang dapat dibebani oleh beban lentur dan beban tekan sekaligus. Seluruh batang dalam struktur frame dapat disebut sebagai struktur balok-kolom. Hanya saja jika pengaruh beban aksial sangat kecil dibandingkan beban lentur, maka akan lebih baik menganalisa struktur tersebut sebagai balok saja, sebaliknya jika beban aksial yang lebih dominan, maka akan lebih baik menganalisanya sebagai struktur kolom. Pada struktur balok-kolom, pengaruh gaya aksial dan beban lentur dipertimbangkan akan sama-sama signifikan. Seperti halnya struktur kolom, struktur balok- kolom juga berpotensi mengalami kegagalan karena buckling atau ketidakstabilan.

Proses penghitungan beban kritis akibat buckling karena pengaruh dari dua beban ini dapat diturunkan dengan konsep mekanika padat $[1,2,3]$. Akan tetapi, penurunan persamaan ini memerlukan kemampuan matematika yang baik. Perbedaan model tumpuan balok-kolom juga akan membuat proses penurunan persamaan beban kritis ini memiliki kesulitan yang bervariasi. Hal ini dirasakan kurang praktis untuk keperluan desain praktis. Makalah ini akan menawarkan persamaan bantu perancangan struktur balok-kolom yang diperoleh melalui penerapakan teknik numerik berbasiskan metode beda hingga (finite difference method). 
Metode beda hingga $(\mathrm{MBH})$ dipilih karena mudah untuk dipahami dan penurunan persamaan matematikanya tidak serumit dibandingkan dengan pendekatan teoritik. Selain itu, metode ini tidak memerlukan skill pemrograman yang cukup tinggi dalam proses komputasinya dibandingkan metode elemen hingga. Walaupun metode ini stabil bersyarat, akan tetapi jika pemilihan lebar intervalnya telah sesuai, maka dari sisi akurasi hasil metode ini cukup memberikan hasil yang baik. Sebagai contoh adalah Ref.[4] yang membahas penghitungan numerik beban kritis buckling struktur kolom taper akibat beban tekan aksial berbasiskan metode beda hingga, dan Ref.[5] yang membahas penghitungan respon dinamik suatu struktur kendaraan.

Makalah ini akan merekomendasikan persamaan bantu desain untuk struktur balok-kolom dalam berbagai variasi tumpuan yang diperoleh dari hasil penghitungan melalui konsep numerik berbasiskan $\mathrm{MBH}$.

\section{METODOLOGI}

Metodologi dari makalah ini dapat dijelaskan sebagai berikut:

\subsection{Penurunan Persamaan Beban Kritis dalam Variasi Tumpuan}

Ada tiga jenis tumpuan untuk struktur balok-kolom yang digunakan pada makalah ini, yaitu: engselrol, jepit-bebas dan jepit-rol, seperti ditunjukan dalam Gambar.1. Balok dengan panjang $L$ dibebani oleh beban lateral terdistribusi sebesar $q$ dan beban aksial $P$.

\subsubsection{Balok-Kolom Tumpuan Engsel-Roller}

Persamaan dasar lendutan pada kolom dengan tumpuan engsel-rol akibat pembebanan tekan aksial dapat dituliskan sebagai berikut:

$-M=-P \cdot y_{i}-\frac{q \cdot x_{i}}{2}\left(L-x_{i}\right)$

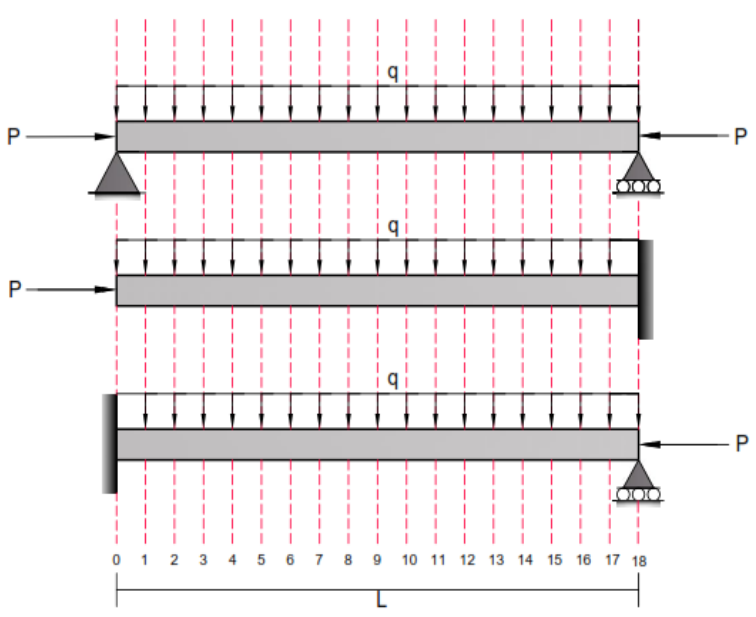

Gambar 1. Pemodelan balok dengan tumpuan engsel-rol, jepit-bebas, jepit-rol

Jika persamaan MBH diterapkan dalam Pers.(1) di atas maka akan diperoleh:

$\frac{d^{2} y}{d x^{2}}=-\frac{M}{E I}=\frac{y_{i-1}-2 y_{i}+y_{i+1}}{\Delta x^{2}}$

Jika diasumsikan

$X=\frac{P . \Delta X^{2}}{E I} ; Y=\frac{q \cdot \Delta X^{2}}{2 E I}$

Sehingga diperoleh persamaan umum balok-kolom tumpuan engsel-rol:

$y_{i-1}-2 y_{i}+X \cdot y_{i}+y_{i+1}=Y \cdot x_{i}\left(x_{i}-L\right)$

Misal balok-kolom dibagi dalam 3 segmen (lihat Gambar 1), sehingga $\Delta x=L / 3$, maka Pers (4) dapat diubah sebagai berikut:

$$
\begin{aligned}
& y_{0}-2 y_{1}+X \cdot y_{1}+y_{2}=Y \cdot x_{1}\left(x_{1}-L\right) \\
& y_{1}-2 y_{2}+X \cdot y_{2}+y_{3}=Y \cdot x_{2}\left(x_{2}-L\right)
\end{aligned}
$$

Kemudian dengan memasukan kondisi syarat batas diperoleh $y(x=0)=y_{0}=0$ dan $y(x=L)=$ $y_{3}=0$. Pers.(5) dan (6) selanjutnya dapat dituliskan dalam bentuk matrik sebagai berikut:

$$
\left[\begin{array}{cc}
-2+x & 1 \\
1 & -2+x
\end{array}\right]\left[\begin{array}{l}
y_{1} \\
y_{2}
\end{array}\right]=\left[\begin{array}{c}
Y \cdot x_{1}\left(x_{1}-L\right) \\
Y \cdot x_{2}\left(x_{2}-L\right)
\end{array}\right]
$$

Dari Pers.(7) ini didapatkan harga lendutan dan perbandingan $P / q$ dari model ini. 


\subsubsection{Balok-Kolom Tumpuan Jepit-Bebas}

Persamaan dasar lendutan pada kolom dengan tumpuan jepit-bebas akibat pembebanan tekan aksial dapat dituliskan sebagai berikut:

$-M=P\left(y_{0}-y_{i}\right)+q \cdot x_{i} \cdot \frac{x_{i}}{2}$

Pers.(8) ini akan diterapkan dalam persamaan MBH (Pers.(2)). Asumsikan harga $X$ dan $Y$ sama dengan Pers.(3), sehingga diperoleh persamaan umum balok-kolom tumpuan jepit-bebas:

$y_{i-1}-2 y_{i}-X\left(y_{0}-y_{i}\right)+y_{i+1}=Y \cdot x_{i}^{2}$

Misal balok-kolom dibagi dalam 3 segmen (lihat Gambar 1), sehingga $\Delta x=L / 3$, maka Pers.(9) dapat diubah sebagai berikut:

$$
\begin{aligned}
& y_{0}-2 y_{1}-X\left(y_{0}-y_{1}\right)+y_{2}=Y \cdot x_{1}^{2} \\
& y_{1}-2 y_{2}-X\left(y_{0}-y_{2}\right)+y_{3}=Y . x_{2}{ }^{2}
\end{aligned}
$$

Kemudian dengan memasukan kondisi syarat batas diperoleh $y(x=0)=y_{0}=0$ dan $y(x=L)=$ $y_{3}=0$. Pers.(10) dan (11) selanjutnya dapat dituliskan dalam bentuk matrik sebagai berikut:

$$
\left[\begin{array}{cc}
1-x & -2+x \\
-x & 1
\end{array}\right]\left[\begin{array}{l}
y_{1} \\
y_{2}
\end{array}\right]=\left[\begin{array}{l}
x_{1}^{2} \\
. x_{2}^{2}
\end{array}\right]
$$

Dari Pers.(12) ini didapatkan harga lendutan dan perbandingan $P / q$ dari model ini.

\subsubsection{Balok-Kolom Tumpuan Jepit-Roller}

Persamaan dasar lendutan pada kolom dengan tumpuan jepit-rol akibat pembebanan tekan aksial dapat dituliskan sebagai berikut:

$-M=-P \cdot y_{i}+q \cdot \frac{x_{i}^{2}}{2}-\frac{5}{8} q \cdot L \cdot x_{i}+\frac{q \cdot L^{2}}{8}$

Pers.(13) ini akan diterapkan dalam persamaan MBH (Pers.(2)). Sehingga diperoleh persamaan umum balok-kolom tumpuan jepit-rol. Jika diasumsikan

$$
X=\frac{P . \Delta X^{2}}{E I} ; Y=\frac{q \cdot \Delta X^{2}}{2 E I} ; c=\frac{q \cdot \Delta X^{2}}{2 E I}
$$

Sehingga diperoleh persamaan umum balok-kolom tumpuan jepit-rol:

$$
y_{i-1}-2 y_{i}+X . y_{i}+y_{i+1}=Y\left(L-5 x_{i}\right)+c . x_{i}^{2}
$$

Misal balok-kolom dibagi dalam 3 segmen (lihat Gambar 1), sehingga $\Delta x=L / 3$, maka Pers.(15) dapat diubah sebagai berikut:

$$
\begin{aligned}
& y_{0}-2 y_{1}+X \cdot y_{1}+y_{2}=Y\left(L-5 x_{1}\right)+c . x_{1}^{2} \\
& y_{1}-2 y_{2}+X . y_{2}+y_{3}=Y\left(L-5 x_{2}\right)+c . x_{2}^{2}
\end{aligned}
$$

Kemudian dengan memasukan kondisi syarat batas diperoleh $y(x=0)=y_{0}=0$ dan $y(x=L)=$ $y_{3}=0$. Pers.(16) dan (17) selanjutnya dapat dituliskan dalam bentuk matrik sebagai berikut:

$$
\left[\begin{array}{cc}
-2+x & 1 \\
1 & -2+x
\end{array}\right]\left[\begin{array}{l}
y_{1} \\
y_{2}
\end{array}\right]=\left[\begin{array}{l}
Y .\left(L-5 x_{1}\right)+c \cdot x_{1}^{2} \\
Y .\left(L-5 x_{2}\right)+c \cdot x_{2}^{2}
\end{array}\right]
$$

\begin{tabular}{|c|c|}
\hline Parameter & Deskripsi \\
\hline Bentuk & Bujur sangkar masiv \\
\hline Penampang & $(b \times h=100 \mathrm{~mm} \times 100 \mathrm{~mm})$ \\
\hline $\begin{array}{l}\text { Panjang Balok- } \\
\text { kolom }\end{array}$ & $\begin{array}{l}500 \mathrm{~mm}, 1000 \mathrm{~mm}, 1500 \mathrm{~mm} \text {, } \\
2000 \mathrm{~mm}, 2500 \mathrm{~mm}, 3000 \mathrm{~mm} \text {, } \\
3500 \mathrm{~mm}, 4000 \mathrm{~mm}, 4500 \mathrm{~mm} \\
\text { dan } 5000 \mathrm{~mm}\end{array}$ \\
\hline Rasio & $17,30,34,60,51,90,69,20$, \\
\hline Kelangsingan & $86,60,103,90,121,20,138,60$, \\
\hline$\lambda=L / \sqrt{I / A}$ & $155,90,173,20$ \\
\hline \multirow{3}{*}{$\begin{array}{l}\text { Kondisi } \\
\text { Tumpuan }\end{array}$} & Engsel - Roller \\
\hline & Jepit - Bebas \\
\hline & Jepit - Roller \\
\hline \multirow{3}{*}{ Material } & Baja 'Structural (ASTM-A36)' \\
\hline & $\sigma_{y}=270 \mathrm{~N} / \mathrm{mm}^{2}$ \\
\hline & $E=210000 \mathrm{~N} / \mathrm{mm}^{2}$ dan $v=0,3$ \\
\hline \multirow{6}{*}{$\begin{array}{l}\text { Kondisi } \\
\text { pembebanan }\end{array}$} & Lateral : \\
\hline & $q=1 \mathrm{~N} / \mathrm{mm}, \mathrm{q}=5 \mathrm{~N} / \mathrm{mm}$ dan \\
\hline & $\mathrm{q}=10 \mathrm{~N} / \mathrm{mm}$ \\
\hline & Aksial : \\
\hline & $P \quad$ diberikan \\
\hline & perlahan \\
\hline
\end{tabular}

Dari Pers.(18) ini didapatkan harga lendutan dan perbandingan $P / q$ dari model ini.

\subsection{Pemodelan Geometri Model Balok-Kolom}

Untuk penghitungan beban kritis buckling balokkolom, digunakan geometri seperti terlihat pada Tabel 1.

Tabel 1 Pemodelan geometri dari balok-kolom 


\subsection{Pembuatan Program Komputasi Penghitungan Beban Kritis}

Suatu program komputasi berbasiskan bahasa Matlab digunakan untuk menghitung beban kritis $P / q$ berdasarkan persamaan-persamaan yang diturunkan dalam subbab 2.1 di atas.

\subsection{Rekomendasi Persamaan Desain Praktis}

Dengan menggunakan teknik regresi kuadrat terkecil (least square regression) pada hasilhasil numerik yang diperoleh, maka suatu persamaan desain praktis untuk penghitungan beban kritis struktur balok kolom dapat direkomendasikan.

\section{HASIL DAN PEMBAHASAN}

\subsection{Penghitungan $P / Q$ Kritis}

Dari Gambar 2 dapat diperkirakan nilai beban kritis struktur balok-kolom dengan panjang $\mathrm{L}=5000 \mathrm{~m}$ untuk ketiga tumpuan yang digunakan. Harga $P / Q$ kritis dipilih tepat di lengkungan kurva pada gambar tersebut. Harga parameter $Q$ merupakan hasil perkalian panjang $L$ dengan beban terdistribusi $q$.

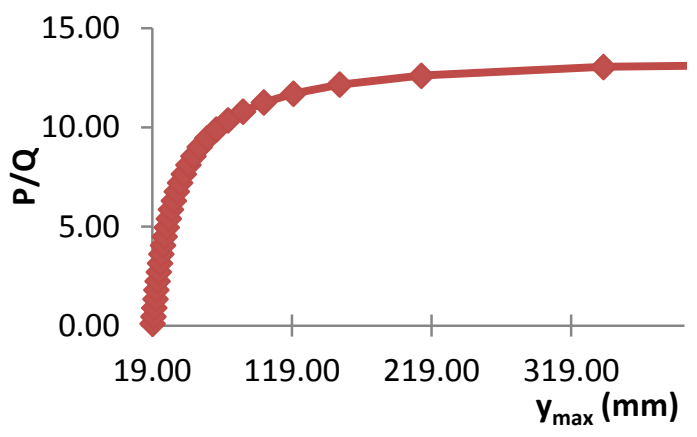

(a)

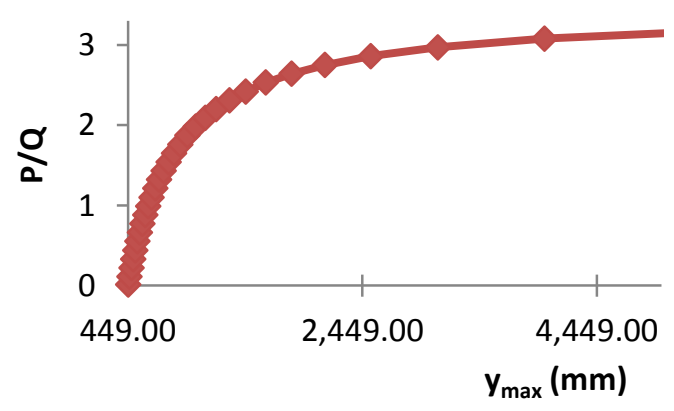

(b)

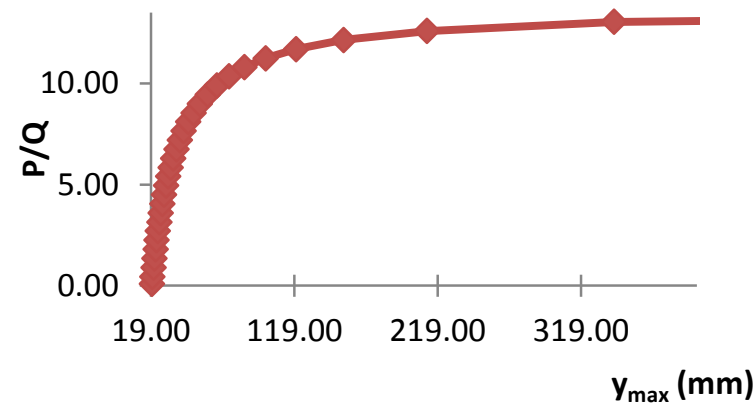

(c)

Gambar 2. Grafik perbandingan beban kritis $P / Q$ vs $y_{\max }$ (a) tumpuan engsel-rol, (b) tumpuan jepitbebas, dan (c) tumpuan jepit-rol

Gambar 2 adalah kurva $P / Q$ terhadap $y_{\max }$ yang dipilih untuk balok dengan rasio kelangsingan $\lambda=173,20$ (atau $\mathrm{L}=5000 \mathrm{~mm}$ ) dan harga beban terdistribusi $q=10 \mathrm{~N} / \mathrm{mm}$ diperoleh harga rasio $P / Q$ kritis sebesar 10 untuk tumpuan engsel-rol, $P / Q=2,6$ untuk tumpuan jepit bebas dan $P / Q=9,8$ untuk tumpuan jepit-rol.

Parameter $y_{\max }$ adalah besarnya perpindahan maksimum yang terjadi pada balok, ketika beban aksial $P=0$, maka harga $y_{\max }$ hanya dipengaruhi oleh beban terdistribusi $q$. Dengan menggunakan tabel lendutan harga $y_{\max }$ pada $\mathrm{P}=0$ diperoleh 19,0 $\mathrm{mm}$ untuk balok dengan tumpuan engsel-roller, 449,0 mm untuk tumpuan jepit-bebas dan 19,0 mm untuk tumpuan jepit-roller.

Harga $P$ diperoleh dari perbandingan $P / Q$ kritis, sedangkan harga momen lentur kritis untuk kasus ini diberikan oleh Pers.(19) untuk tumpuan engselroller, Pers.(20) untuk tumpuan jepit-bebas dan Pers.(21) untuk tumpuan jepit-roller.

$M=-P \cdot y_{i}-\frac{q \cdot x_{i}}{2}\left(L-x_{i}\right)$

$M=P\left(y_{0}-y_{i}\right)+q \cdot x_{i} \cdot \frac{x_{i}}{2}$

$M=-P \cdot y_{i}+q \cdot \frac{x_{i}^{2}}{2}-\frac{5}{8} q \cdot L \cdot x_{i}+\frac{q \cdot L^{2}}{8}$

Kemudian hasil dari penghitungan tegangan kritis $\left(\sigma_{\max }\right)$ dievaluasi dengan menggunakan Pers.(22). $\sigma_{\max }=\frac{P}{A}+\frac{M \cdot c}{I}$ 
Tabel 4.2 Harga beban kritis tumpuan engsel-rol

\begin{tabular}{|c|c|c|c|c|c|c|}
\hline \multirow{2}{*}{$\lambda i$} & \multicolumn{2}{|c|}{$q=1 \mathrm{~N} / \mathrm{mm}$} & \multicolumn{2}{c|}{$q=5 \mathrm{~N} / \mathrm{mm}$} & \multicolumn{2}{c|}{$q=10 \mathrm{~N} / \mathrm{mm}$} \\
\cline { 2 - 7 } & $P / Q$ & $\sigma(\mathrm{MPa})$ & $P / Q$ & $\sigma(\mathrm{MPa})$ & $P / Q$ & $\sigma(\mathrm{MPa})$ \\
\hline$* 17,30$ & 114000,00 & 5700,19 & 21114,00 & 5279,44 & 11934,00 & 5968,88 \\
$* 34,60$ & 15136,00 & 1514,35 & 2736,00 & 1371,75 & 1425,00 & 1432,50 \\
$* 51,90$ & 4444,00 & 668,29 & 782,00 & 644,94 & 408,00 & 628,88 \\
$* 69,20$ & 1680,00 & 339,00 & 294,00 & 319,01 & 168,00 & 366,01 \\
\hline 86,60 & 800,00 & 204,69 & 161,00 & 224,70 & 90,00 & 241,89 \\
103,90 & 462,00 & 165,35 & 92,00 & 151,76 & 50,40 & 180,73 \\
121,20 & 322,00 & 121,89 & 55,00 & 142,21 & 29,90 & 136,56 \\
138,60 & 207,00 & 94,80 & 39,10 & 86,22 & 18,70 & 82,85 \\
155,90 & 133,00 & 75,04 & 25,20 & 70,67 & 13,80 & 68,04 \\
173,20 & 90,00 & 63,76 & 20,70 & 58,54 & 9,45 & 55,83 \\
\hline
\end{tabular}

Tabel 4.3 Harga beban kritis tumpuan jepit-bebas

\begin{tabular}{|c|c|c|c|c|c|c|}
\hline \multirow{2}{*}{$\lambda i$} & \multicolumn{2}{|c|}{$q=1 \mathrm{~N} / \mathrm{mm})$} & \multicolumn{2}{c|}{$q=5 \mathrm{~N} / \mathrm{mm}$} & \multicolumn{2}{c|}{$q=10 \mathrm{~N} / \mathrm{mm}$} \\
\cline { 2 - 7 } & $P / Q$ & $\sigma(\mathrm{MPa})$ & $P / Q$ & $\sigma(\mathrm{MPa})$ & $P / Q$ & $\sigma(\mathrm{MPa})$ \\
\hline$* 17,30$ & 29900.00 & 1495,00 & 5980,00 & 1495,00 & 2938,00 & 1469,00 \\
$* 34,60$ & 3744,00 & 374,40 & 743,60 & 371,80 & 371,80 & 371,80 \\
\hline 51,90 & 1105,00 & 165,75 & 221,00 & 165,75 & 109,20 & 163,80 \\
69,20 & 462,80 & 92,56 & 84,00 & 84,00 & 40,80 & 81,60 \\
86,60 & 227,50 & 56,88 & 45,00 & 56,25 & 20,70 & 51,75 \\
103,90 & 120,00 & 36,00 & 24,00 & 36,00 & 11,50 & 34,50 \\
121,20 & 82,50 & 28,88 & 15,60 & 27,30 & 7,59 & 26,57 \\
138,60 & 52,80 & 21,12 & 9,20 & 18,40 & 5,06 & 20,24 \\
155,90 & 34,50 & 15,53 & 7,13 & 16,04 & 3,45 & 15,53 \\
173,20 & 25,30 & 12,65 & 5,29 & 13,23 & 2,42 & 12,10 \\
\hline
\end{tabular}

Tabel 4.4 Harga beban kritis tumpuan jepit-rol

\begin{tabular}{|c|c|c|c|c|c|c|}
\hline \multirow{2}{*}{$\lambda i$} & \multicolumn{2}{|c|}{$q=1 \mathrm{~N} / \mathrm{mm}$} & \multicolumn{2}{c|}{$q=5 \mathrm{~N} / \mathrm{mm}$} & \multicolumn{2}{c|}{$q=10 \mathrm{~N} / \mathrm{mm}$} \\
\cline { 2 - 7 } & $P / Q$ & $\sigma(\mathrm{MPa})$ & $P / Q$ & $\sigma(\mathrm{MPa})$ & $P / Q$ & $\sigma(\mathrm{MPa})$ \\
\hline$* 17,30$ & 104500,00 & 5225,19 & 20196,00 & 5049,94 & 9639,00 & 4821,38 \\
$* 34,60$ & 12054,00 & 1206,15 & 2394,00 & 1200,75 & 1197,00 & 1204,50 \\
$* 51,90$ & 3910,00 & 588,19 & 714,00 & 543,94 & 357,00 & 552,38 \\
$* 69,20$ & 1501,50 & 303,30 & 294,00 & 309,01 & 147,00 & 314,01 \\
\hline 86,60 & 766,50 & 196,31 & 147,00 & 207,20 & 75,60 & 205,89 \\
103,90 & 441,00 & 139,05 & 84,00 & 129,76 & 44,10 & 119,83 \\
121,20 & 286,00 & 109,29 & 54,60 & 101,51 & 27,30 & 97,46 \\
138,60 & 193,60 & 89,44 & 35,70 & 81,42 & 17,85 & 81,45 \\
155,90 & 131,25 & 74,26 & 25,20 & 67,67 & 12,60 & 65,64 \\
173,20 & 90,00 & 63,76 & 18,90 & 58,04 & 9,45 & 54,83 \\
\hline
\end{tabular}

Catatan: *kegagalan akibat plastisitas 
Jika nilai $\sigma_{\max }$ lebih besar dari nilai tegangan luluh $\sigma_{y}$ material yang digunakan, dimana $\sigma_{y}=270,0$ $\mathrm{N} / \mathrm{mm}^{2}$, maka berarti kegagalan struktur terjadi bukanlah karena buckling melainkan karena adanya proses peluluhan/plastisitas, seperti yang diberikan pada Tabel 2 sampai Tabel 4.

\subsection{Persamaan Desain Praktis yang Direkomendasikan}

Jika hasil pada subbab 3.1 digambarkan dalam hubungan $P / Q$ dengan rasio kelangsingan $(\lambda)$, maka akan diperoleh hubungan seperti yang diperlihatkan pada Gambar 3. Pada beban lateral $q$ yang sama, balok-kolom yang lebih pendek memiliki harga beban kritis yang jauh lebih tinggi dengan lendutan kecil dibandingkan balok-kolom yang panjang. Sedangkan untuk balok-kolom dengan panjang yang sama, balok-kolom dengan $q$ yang lebih kecil memiliki harga beban kritis yang lebih tinggi dibandingkan dengan balok-kolom dengan harga $q$ yang besar.

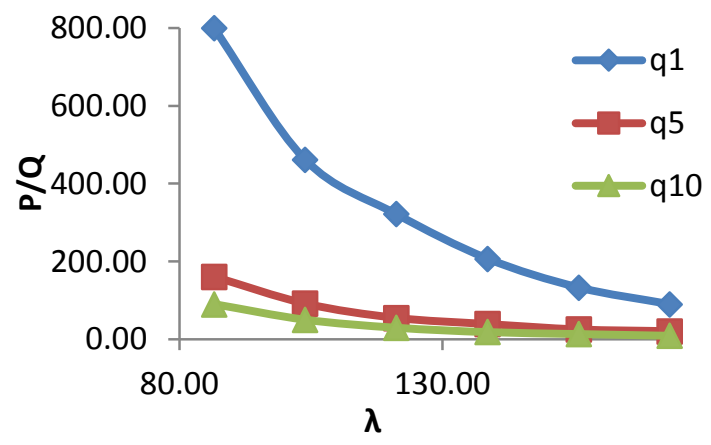

(a)

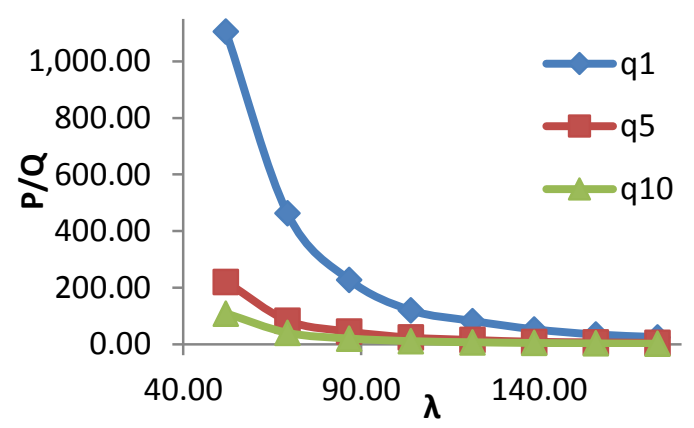

(b)

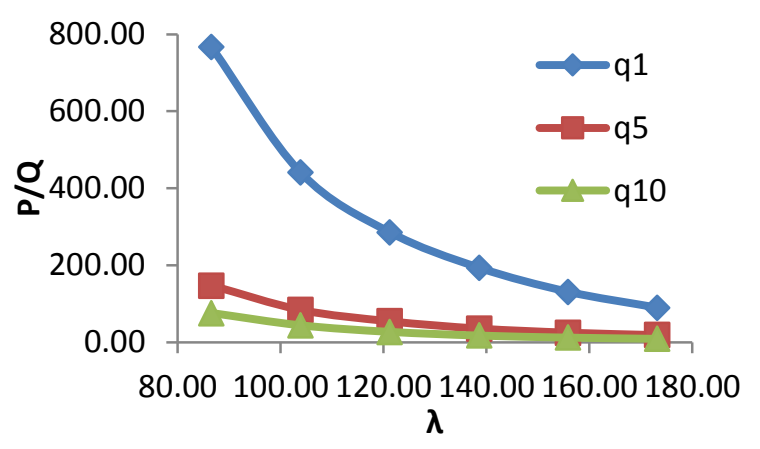

(c)

Gambar 3 Grafik $P / Q$ vs $\lambda$ (a) tumpuan engsel-rol, (b) tumpuan jepit-bebas, dan (c) tumpuan jepit-rol

Dari Gambar 3 kemudian didekati dengan menggunakan teknik regresi kuadrat terkecil (least square regression) dengan menggunakan sebuah model pendekatan seperti yang ditunjukkan oleh Pers.(23). Pada model ini, harga $\lambda$ dinyatakan sebagai $x_{1}$, variasi beban lateral terdistribusi $q$ dinyatakan sebagai $x_{2}$, sedangkan patameter $P / Q$ kritis dinyatakan dalam parameter $y$.

$$
y=a_{0}+a_{1} x_{1}+a_{2} x_{2}+a_{3} x_{1} x_{2}+a_{4} x_{1}^{2}+a_{4} x_{1}^{2} x_{2}
$$

Tingkat kesesuaian yang diperoleh untuk tiga jenis variasi tumpuan memberikan hasil kesesuaian di atas $96 \%$ sehingga cukup layak untuk digunakan sebagai model pendekatan (Lihat Tabel 2). Ini berarti persamaan pendekatan untuk menghitung beban kritis balok-kolom diperoleh jika parameter $x_{1} x_{2}$ dan $y$ diganti dengan harga-harga yang semestinya, maka persamaan desain sederhana beban kritis balok-kolom ini dapat dihitung dengan persamaan-persamaan yang diberikan dalam Tabel 2. 
Tabel 2 Tingkat Kesesuaian Persamaan Pendekatan Tumpuan Engsel-Rol

\begin{tabular}{|c|c|c|c|}
\hline Model & Hasil Regresi & $\begin{array}{c}\text { Range } \\
\text { Penggunaan }\end{array}$ & $\begin{array}{c}\text { Tingkat } \\
\text { Kesesuaian }\end{array}$ \\
\hline Pin-Roller & $\begin{aligned} y= & 3129.48-32.91 x_{1}-465.71 x_{2}+0.09 x_{1}^{2}+16.54 x_{2}^{2} \\
& +3.23 x_{1} x_{2}-0.003 x_{1}^{2} x_{2}-0.00001 x_{1} x_{2}^{2}-0.0006 x_{1}^{2} x_{2}^{2}\end{aligned}$ & $86,6 \leq \lambda \leq 173,2$ & $98.21 \%$ \\
\hline Jepit-Bebas & $\begin{aligned} y= & 3248.867-47.184 x_{1}-800.843 x_{2}+0.169 x_{1}^{2}+50.043 x_{2}^{2} \\
& +11.616 x_{1} x_{2}-0.042 x_{1}^{2} x_{2}-0.726 x_{1} x_{2}^{2}-0.003 x_{1}^{2} x_{2}^{2}\end{aligned}$ & $51,9 \leq \lambda \leq 173,2$ & $96.90 \%$ \\
\hline Jepit-Roller & $\begin{aligned} y= & 3085.171-33.149 x_{1}-460.438 x_{2}+0.092 x_{1}^{2}+15.599 x_{2}{ }^{2} \\
& +3.369 x_{1} x_{2}-0.004 x_{1}^{2} x_{2}-0.00002 x_{1} x_{2}^{2}-0.001 x_{1}^{2} x_{2}{ }^{2}\end{aligned}$ & $86,6 \leq \lambda \leq 173,2$ & $99.12 \%$ \\
\hline
\end{tabular}

\section{KESIMPULAN}

Beberapa kesimpulan yang diperoleh melalui makalah ini adalah:

1. Penghitungan beban kritis dengan metode MBH memberikan hasil yang cukup akurat dimana tingkat error yang diperoleh berkisar dibawah $1 \%$ untuk setiap tipe tumpuan.

2. Beban kritis balok-kolom dibawah suatu pembebanan terdistribusi $q$, dipengaruhi oleh rasio kelangsingan dan jenis tumpuan. Harga ini berubah jika nilai $q$ dan panjang $L$ divariasikan.

3. Harga beban kritis yang diperoleh hanya berlaku ketika balok-kolom dalam kondisi elastis, sehingga ada batas minimum rasio kelangsingan balok-kolom, dimana untuk tumpuan engsel-rol dan jepit-rol, batasannya $\lambda$ $\geq 86.60$, sedangkan untuk tumpuan jepitbebas $\lambda \geq 2.42$.

4. Dari hasil numerik, dapat diperoleh suatu persamaan desain praktis yang direkomendasikan dalam menghitung beban kritis dengan menggunakan teknik integrasi least square metahod.

\section{UCAPAN TERIMA KASIH}

Makalah ini merupakan salah satu luaran dari Penelitian Dasar Fundamental tahun 2017. Oleh karena itu penulis mengucapkan terimakasih banyak atas dana yang diberikan oleh Kemenristekdikti Indonesia untuk penelitian ini.

\section{DAFTAR PUSTAKA}

[1] W. F. Chen. Structural Stability, New York: Elsevier, 1987.

[2] J. Gere. Mechanics of Materials Sixth Edition. Singapura: Thomson Learning, 2004.

[3] G. Saha, S. Banu. "Buckling Load Of A Beam-Column For Different End Conditions Using Multi-Segment Integration Technique", ARPN Journal of Engineering and Applied Sciences, Vol. 2, No. 1, 2007.

[4] E. Satria, F. Kurnia, J. Malta, dan M. Bur. "Penghitungan Numerik Beban Kritis Buckling Struktur Kolom Taper Akibat Beban Tekan Aksial Berbasiskan Metode Beda Hingga". Proceeding Seminar Nasional Tahunan Teknik Mesin XIV, Banjarmasin, 2015.

[5] E. Satria. Jawab Dinamik Sistem Benda Kaku, Tugas Akhir, Padang: Universitas Andalas, 1999.

\section{NOMENKLATUR}

M Momen lentur (N.mm)

E Modulus elastisitas (MPa)

I Momen inersia $\left(\mathrm{mm}^{4}\right)$

P Beban aksial $(\mathrm{N})$

q Beban terdistribusi (N/mm)

Q Beban terkonsentrasi akibat beban terdistribusi $(\mathrm{N})$

L Panjang balok (mm)

y Lendutan balok dalam arah lateral ( $\mathrm{mm})$ 
$\mathrm{y}_{\max } \quad$ Lendutan balok maksimum (mm)

$\lambda$ Rasio kelangsingan

A Luas penampang $\left(\mathrm{mm}^{2}\right)$

$\sigma_{y} \quad$ Tegangan luluh (MPa)

$\sigma_{\max } \quad$ Tegangan kritis (MPa) 